\title{
SCADA SYSTEM FOR A DIDACTIC TYPE WATER MANAGEMENT PLANT
}

\section{GERMÁN MORALES R., LUIS A. VARELA R \& JULIÁN R. CAMARGO L}

Engineering Faculty, Universidad Distrital Francisco José de Caldas, Bogotá, Colombia

\begin{abstract}
This paper presents the water management process with FESTO's MPS-PA didactic modules, which have four individually configurable operating stations, each one including an analog sensor and an analog actuator allowing to control each one of the variables using a PID type controller, a touch screen for each module from which an HMI (Human Machine Interface) was implemented, a PLC for each module which is programmed with two different languages, GRAFCET and structured language. On the other hand, the operation of the machines can be done remotely through a system of remote control and supervision of industrial processes (SCADA).

KEYWORDS: Automation, HMI, PID, Pressure, SCADA
\end{abstract}

Received: Jun 08, 2020; Accepted: Jun 28, 2020; Published: Oct 07, 2020; PaperId.: IJMPERDJUN20201484

\section{INTRODUCTION}

The economic and productive development of a country requires the implementation of technology at different levels of productivity, to generate economic growth due to increased production, reduce operating costs and encourage the professional growth of operators and technicians involved in the various processes.

Automation processes not only improve the quality of the final products but are also necessary for innovation and the generation of new employment opportunities at different production levels. The country must stop being a consumer of machinery and automated processes brought from abroad. Creating and implementing automated processes would generate a great benefit, mainly in terms of reducing costs generated by imports and tariffs on this equipment [1]. If this is the case, the country can become a distributor in the region of certain equipment and products that are manufactured [2], [3].

The approach of an automated system can be implemented at different levels, which means that a simple and limited production process can be extrapolated and developed in a large industry. There is a wide variety of structures in the PI controllers and in general in the PID controllers that have been proposed throughout history. As [4] suggests, an important reason why the structures are not standardized is due to the transition from pneumatically operated controllers to electronic implementation and now to microprocessor implementation.

Usually, functional blocks and sequential algorithms are combined with PID controllers. Many regulatory control strategies, followers, start and stop, can be designed around a classical PID controller. This provides the basic means for good regulatory control, smooth transitions and fast start/stop [5], [6].

Few industries have as many facets or are as interesting as the process industry, which manufactures a wide range of products for the most diverse sectors of life.

On the one hand, the chemical industry manufactures preliminary products for other industries. This group 
includes basic chemicals, petrochemicals, polymers, as well as refined and specialty chemicals. Its key customers are the automotive industry and the construction and packaging industries.

Furthermore, the chemicals are used in the areas of health, environment and nutrition. Like the chemical andpharmaceutical industry, the process industry includes other sectors such as biotechnology and the paper and food industries.Although the end products may differ, automation makes great advances in each of these areas. International competition and the resulting pressure to constantly increase productivity, as well as the continuous expansion of variants, strict requirements for processes and quality assurance, demand solutions for automation [7].

In this paper, the development of an automated system is presented in a basic and simple way, so that it can be adjusted to different production requirements.

\section{SYSTEM COMPONENTS AND VARIABLES}

The MPS-PA FESTO modules are composed of a wide variety of components that will allow the development of different skills for the implementation of any automation process thanks to the concepts covered [8]. Next, each one of the components of the station and its function will be shown, as well as the identification of each one of the variables that will give rise to the bases of the programming of the PLC of each one of the stations.

\subsection{Filtering module}

This module has the components presented in Table 1, whose location is shown in Figure 1.

Table1: Filter module components

\begin{tabular}{|c|l|l|}
\hline & \multicolumn{1}{|c|}{ Component } & \multicolumn{1}{c|}{ Function } \\
\hline 1 & Cutter valve & Allows water to pass through \\
\hline 2 & Filter & Water Filtration \\
\hline 3 & Butterfly valve & Allows water to pass through \\
\hline 4 & Ball valve & $\begin{array}{l}\text { Water flow to the mixing } \\
\text { module }\end{array}$ \\
\hline 5 & Tank 1 & Stores water to be treated \\
\hline 6 & Tank 2 & Stores filtered water \\
\hline 7 & Barometer & Pressure measurement \\
\hline 8 & Pump 1 & Pumps water from tank 1 \\
\hline 9 & Pump 2 & Pumps water from tank 2 \\
\hline 10 & Emergency stop & It stops the whole process \\
\hline 11 & Touch screen & HMI \\
\hline 12 & Industrial control & \\
\hline 13 & PLC & Control system \\
\hline 14 & Control circuit & \\
\hline 15 & Indicator & Shows status of the process \\
\hline
\end{tabular}

The water in tank 1 passes through the filter thanks to motor number one and the open knife valve, this can be seen when the butterfly valve indicator is yellow. As the water passes through the filter, it is stored in the second tank until the second tank is full or the first tank is empty. 


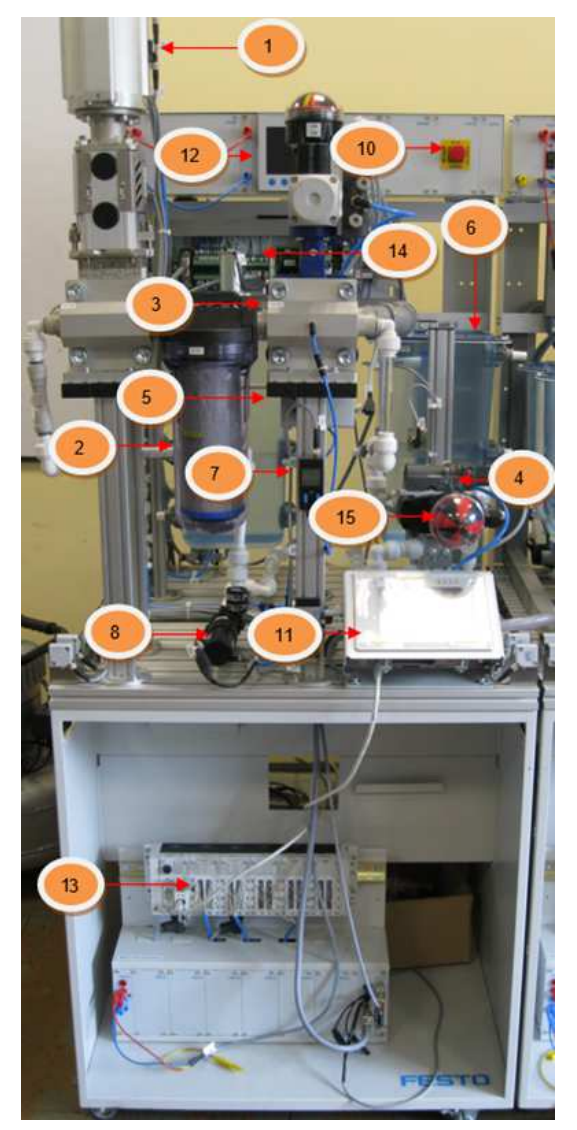

Figure 1: Distribution of components in the filter module

When either of these two conditions is met, a small portion of the filtered water from tank two returns to tank one. For this procedure to take place, the knife valve changes its position, as well as the indicator on the knife valve which changes to red as these two valves work together and at the same time the airflow is activated. This part of the procedure is done to clean the filter with a combination of water and air that removes the particles and sends them back to tank one.

Finally, pump number two is activated along with the ball valve and the water in tank two is passed to the next module, the mixing module, until tank two is empty or the tank in the mixing module is full. The amount of water can be determined by the capacitive sensors at the bottom and top of each tank mentioned above.

\subsection{Mixing module}

The parts that make up this module are listed in Table 2.

Table 2: Mixing module components

\begin{tabular}{|c|l|l|}
\hline & \multicolumn{1}{|c|}{ Component } & \multicolumn{1}{c|}{ Function } \\
\hline 1 & Tank 1 & Mixing tank 1 \\
\hline 2 & Tank 2 & Mixing tank 2 \\
\hline 3 & Tank 3 & Mixing tank 3 \\
\hline 4 & Tank 4 & $\begin{array}{l}\text { Mixture storage tank (main } \\
\text { tank) }\end{array}$ \\
\hline 5 & Valve and indicator & Shows status of the process \\
\hline 6 & Pump 1 & Extracts water from the tank \\
\hline 7 & Pump 2 & Extracts water from the tank \\
\hline 8 & PLC & Control system \\
\hline 9 & Control circuit & \\
\hline
\end{tabular}




\begin{tabular}{|l|l|l|}
\hline 10 & Industrial control & \\
\hline 11 & Flowmeter & Measures process flow \\
\hline 12 & Touch screen & HMI \\
\hline 13 & Barometer & \\
\hline 14 & Safety Float & Prevents water overflow \\
\hline
\end{tabular}

Figure 2 shows each of the components of the module, except for the two pumps and the barometer behind the tanks.

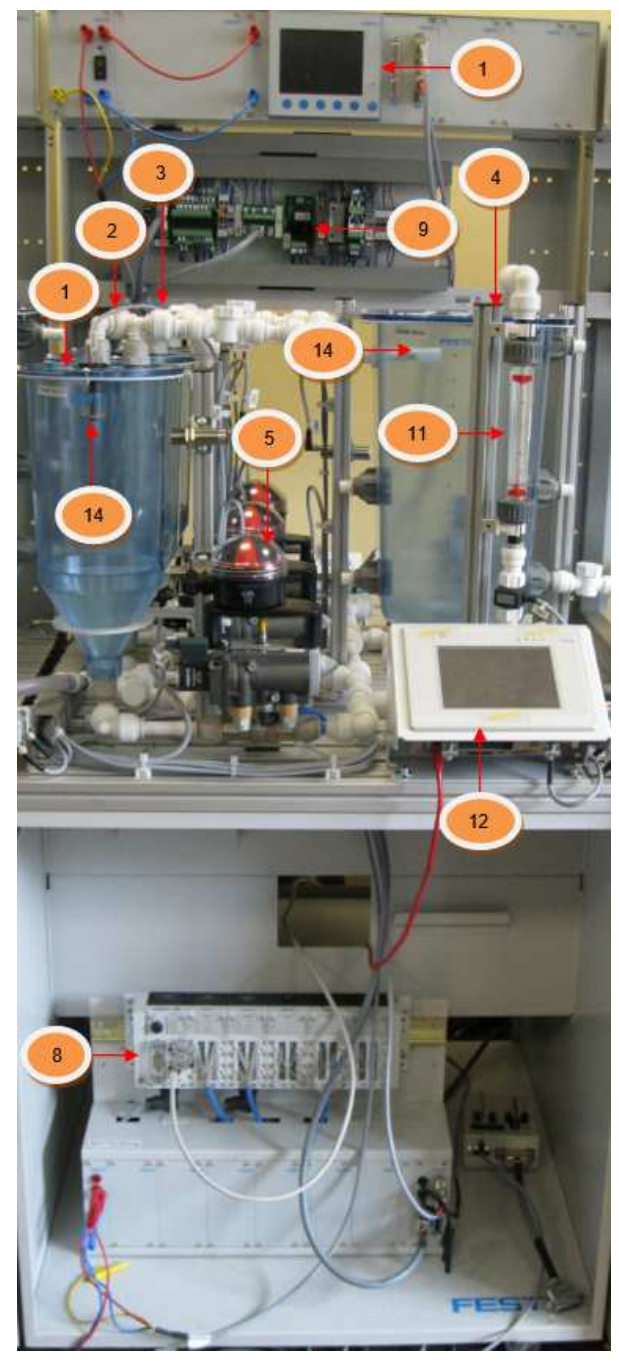

Figure 2: Distribution of components in the mixing module

In this module, the water received from tank two of the filtration station is now mixed with some diluted components found in tanks two and three of the mixing station to be taken to the main tank.

The main process to be carried out will have a specific order. When tank number one is filled, pump number one and valve number one will be activated until it is empty. This will allow water from tank one to flow into tank four or the main tank. The same is true for tanks two and three.

Each tank has a sensor at the bottom which will allow the stop command to be given since one of the safety conditions is that the pumps do not run empty.Also, each tank has a float in the upper part so that if it is activated, any 
actuator including those of the other modules will stop working to prevent the water from overflowing.

\subsection{Reactor module}

The reactor module is composed of each of the elements presented in Table 3.

Table 3: Reactor module components

\begin{tabular}{|l|l|l|}
\hline & \multicolumn{1}{|c|}{ Component } & \multicolumn{1}{c|}{ Function } \\
\hline 1 & Industrial controller & \\
\hline 2 & Emergency stop & It stops the whole process \\
\hline 3 & Control circuit & \\
\hline 4 & Mixer motor & Extracts elements for mixing with water \\
\hline 5 & Safety Float & Prevents water overflow \\
\hline 6 & Tank & Stores the result of the mixing \\
\hline 7 & Upper-level sensor & Prevents tank overflow \\
\hline 8 & Lower level sensor & Prevents pumps from running under vacuum \\
\hline 9 & Pump one & \\
\hline 10 & Pump two & Pumps water to \\
\hline 11 & PT-100 temperature sensor & Used in water temperature control \\
\hline 12 & Heater & Heats the water \\
\hline 13 & Touch screen & HMI \\
\hline 14 & PLC & Control system \\
\hline
\end{tabular}

As you can see in Figure 3, in this module you can make use of new components such as the PT-100 temperature sensor and the heater that will be activated according to the control that will be seen later. There is also a second pump behind the touch screen which makes the water flow to the last station.

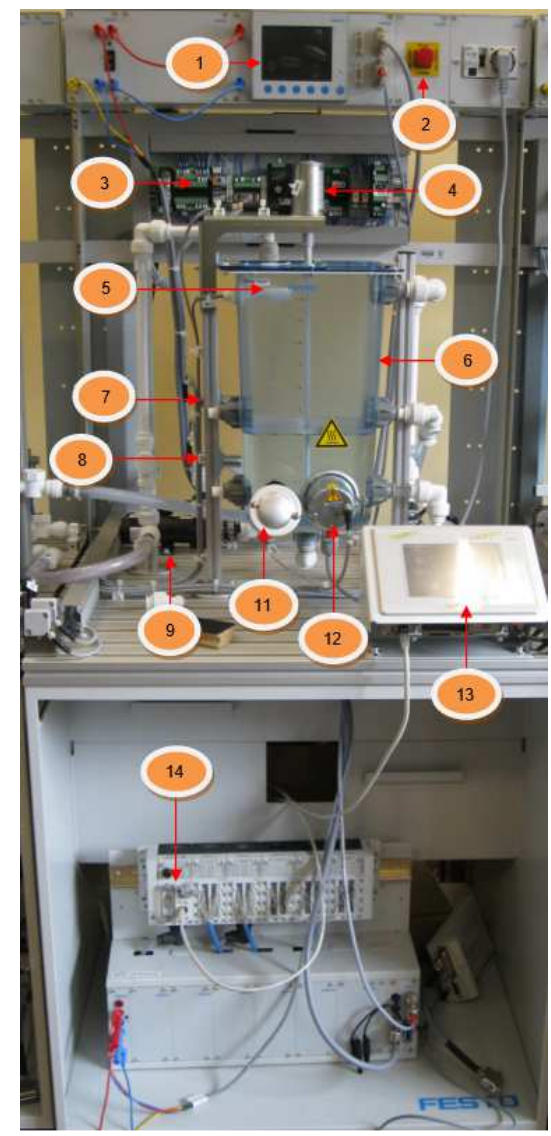

Figure 3: Distribution of components in the reactor module 
The automatic process to be applied in this station is quite simple. Simply the water received from the mixing module will be heated to a temperature that will remain thanks to the control that will be exerted on the resistance for a time until the water is taken to the next module, the bottling module.If desired, each of the modules can be controlled manually through the touch screen or the SCADA.

\subsection{Bottling Module}

The last module (bottling) is composed of the parts presented in Table 4.

Table 4: Bottling module components

\begin{tabular}{|l|l|l|}
\hline & \multicolumn{1}{|c|}{ Component } & \multicolumn{1}{c|}{ Function } \\
\hline 1 & Industrial controller & \\
\hline 2 & Dosing tank & Fills the bottles \\
\hline 3 & Control circuit & \\
\hline 4 & Safety Float & Prevents water overflow \\
\hline 5 & Tank 1 & Stores final blend \\
\hline 6 & Dispenser & Doses quantity of water in the bottles \\
\hline 7 & Pneumatic tweezers & Controls the route of the bottles \\
\hline 8 & Conveyor belts & $\begin{array}{l}\text { Transport of bottles for water } \\
\text { packaging }\end{array}$ \\
\hline 9 & Touch screen & HMI \\
\hline 10 & PLC & Control system \\
\hline
\end{tabular}

The module also has a pump behind the horizontal conveyor belt which will be controlled by a PID control so that the level in the dosing tank remains constant at all times (Figure 4). The module also has a distance sensor at the top of the dosing tank which will allow the level to be set exactly.

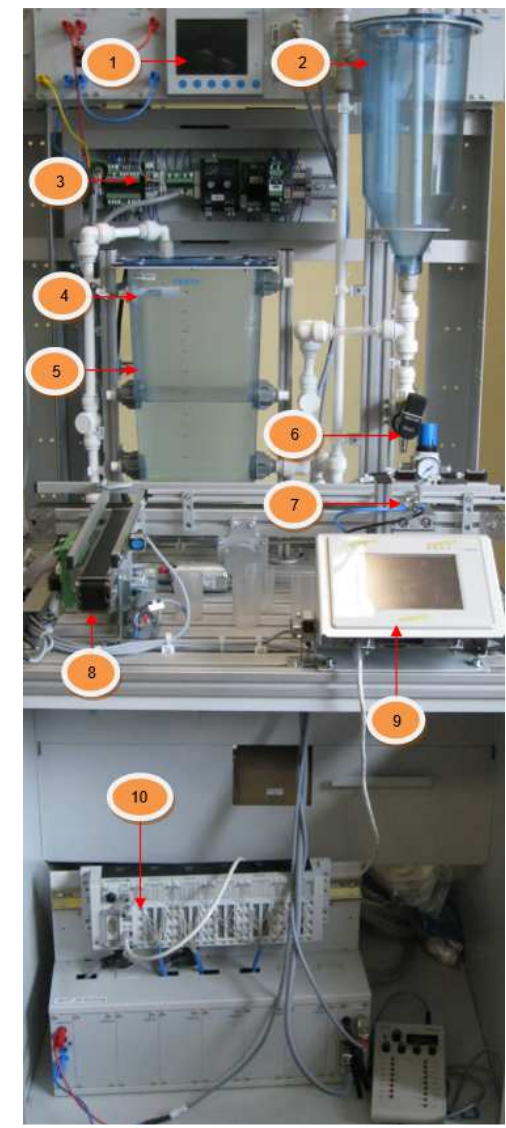

Figure 4: Distribution of components in the bottling module 
In the bottling process, water is received from the reactor module to the main storage tank; a pump that will be controlled with PID will fill the dosage tank to a constant level and the valve at the bottom of the tank will allow the bottles to be filled. The bottles will be dragged by the conveyor belt to the point just below the dosing tank. The program made for the automatic process activates the pneumatic arm which stops the bottle thanks to the detection of the object by the sensor that is there and at the end of the filling of the bottle the arm releases it allowing its final route.

\subsection{Bottling module}

The identification of variables is done with a simulation box that allows visualizing the variables corresponding to the sensors and as you can see in the figure each LED and each switch has a corresponding bit, in this case, the LED indicators are associated to the input bits and the switches to the output bits (Figure 5).

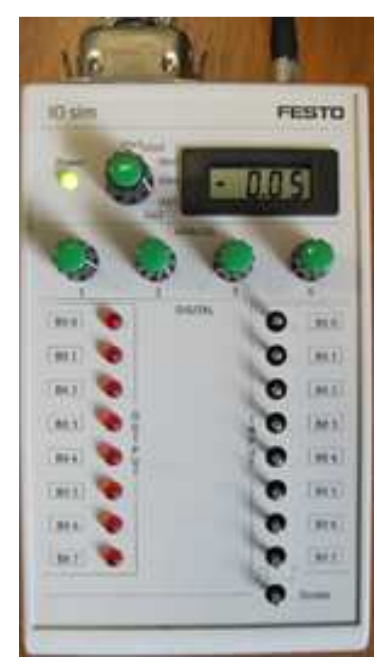

Figure 5: Simulation box

To be able to identify the addresses in an exact way it is necessary to observe the variables from the Codesys [9] tool, in which the GrafCet language and the resources to be used are selected. Besides, the corresponding network addresses can be assigned for each one of the vast variables of each one of the modules, to work from a single point.

The addresses of each of the input variables can be seen in Table 5, for the output variables Table 6 shows this information.

Table 5: Input variable recognition

\begin{tabular}{|l|l|l|}
\hline \multicolumn{3}{|c|}{ Input variables Filter stage } \\
\hline Bit & Address & Description \\
\hline 1 & $\%$ IX2.1 & Tank Top Sensor 1 \\
\hline 2 & $\%$ IX2.2 & Lower Tank Sensor 1 \\
\hline 3 & $\%$ IX2.3 & Tank Top Sensor 2 \\
\hline 4 & $\%$ IX2.4 & Lower Tank Sensor 2 \\
\hline 5 & IX2.5 & Position of the cutter \\
\hline \multicolumn{3}{|c|}{ Input variables Mixing stage } \\
\hline Bit & Address & Description \\
\hline 1 & $\%$ IX2.1 & Tank Height Sensor 1 \\
\hline 2 & $\%$ IX2.2 & Under Tank Sensor 1 \\
\hline 3 & $\%$ IX2.3 & Single Sensor (Low) Tank 2 \\
\hline 4 & IX2.4 & Single Sensor (Low) Tank 3 \\
\hline 5 & \%X2.5 & High Mixing Tank Sensor \\
\hline
\end{tabular}




\begin{tabular}{|l|l|l|}
\hline 6 & $\%$ IX2.6 & Under Mixing Tank Sensor \\
\hline \multicolumn{3}{|c|}{ Input variables Reactor stage } \\
\hline Bit & Address & Description \\
\hline 1 & $\%$ IX2.1 & Low tank sensor \\
\hline 2 & $\%$ IX2.2 & Upper tank sensor \\
\hline \multicolumn{3}{|c|}{ Input variables Bottling stage } \\
\hline Bit & Address & Description \\
\hline 1 & $\%$ IX2.1 & High tank level \\
\hline 2 & $\%$ IX2.2 & Low tank level sensor \\
\hline 3 & $\%$ IX2.3 & Bottle sensor at the beginning of the band \\
\hline 4 & $\%$ IX2.4 & Bottle sensor for filling \\
\hline 5 & $\%$ IX2.5 & Bottle sensor at the end of the band \\
\hline
\end{tabular}

Table 6: Output variable recognition

\begin{tabular}{|l|l|l|}
\hline \multicolumn{3}{|c|}{ Output variables Filter stage } \\
\hline Bit & Address & Description \\
\hline 0 & \%QX0.0 & Analog Actuator Bit \\
\hline 1 & \%X0.1 & Pump 1 \\
\hline 2 & \%X0.2 & Pump 2 \\
\hline 3 & \%Q0.3 & Knife Valve (Valve 1) \\
\hline 4 & \%X0.4 & Valve 2 (Fluid flow to station 2) \\
\hline 5 & \%QX0.5 & Mixer \\
\hline \multicolumn{3}{|c|}{ Output variables Mixing stage } \\
\hline Bit & Address & Description \\
\hline 0 & \%X0.0 & Analog Pump Trigger \\
\hline 1 & \%X0.1 & Pump 2 \\
\hline 2 & \%X0.2 & Tank 1 shut-off valve \\
\hline 3 & \%X0.3 & Tank 2 Flow Valve \\
\hline 4 & \%X0.4 & Tank 3 shut-off valve \\
\hline \multicolumn{3}{|c|}{ Output variables Reactor stage } \\
\hline Bit & Address & Description \\
\hline 0 & \%QX0.0 & Resistance \\
\hline 1 & \%QX0.1 & Recirculation pump 2 \\
\hline 2 & \%QX0.2 & Return pump 1 \\
\hline 3 & \%QX0.3 & Mixer \\
\hline Output variables Bottling stage \\
\hline Bit & Address & Description \\
\hline 0 & \%QX0.0 & Analogic actuator (pump) \\
\hline 1 & \%QX0.1 & Filling valve \\
\hline 2 & \%QX0.2 & Bands \\
\hline 3 & \%QX0.3 & Pneumatic arm \\
\hline \multicolumn{3}{|c|}{} \\
\hline
\end{tabular}

Each of the input and output variables is used in the programming of the PLC's included in each module so that each station component acts as required to complete the process.

\section{CONTROLLER DESIGN AND TESTING}

Each of the modules has an actuator that can be controlled digitally or analogically and a sensor that accounts for the analog variable being handled in each module, so a derivative proportional continuous control is implemented for two cases and an integral proportional continuous control for the other two modules due to the nature of the variable being handled [10], [11]. 
The MPS-PA stations have an industrial controller which allows implementing a control system over the mentioned variables depending on the parameters entered through the display screen. The variables to handle are pressure for the filtering station, flow for the mixing station, temperature for the reactor and last level for the filling or bottling station. However, the PID control will only be performed in the slow-reacting stations, i.e. for the reactor and the bottling station. The filtering and mixing stations will be controlled by a PI system given the speed of response required.

\subsection{Empirical adjustment method for Ziegler-Nichols slow-motion controllerse}

This method is perfect for S-shaped graphical responses as shown in Figure 6 and the following steps need to be followed to achieve this [12]:

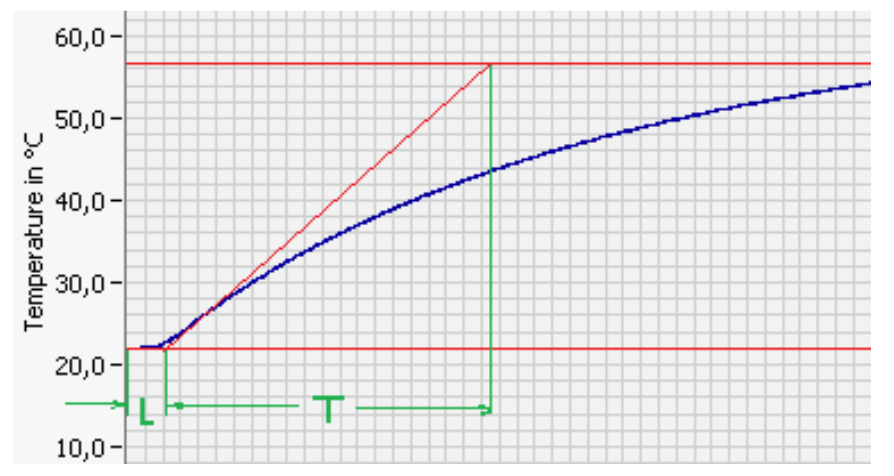

Figure 6: S-shaped response obtained from the reactor station

- Open the control loop and adjust the proportional gain $(\mathrm{Kp}=1)$ and cancel the integral and derivative gains.

- Apply a sharp change to the control variable by changing the "set point".

- $\quad$ Record graphically the evolution over time of the process variable PV.

- Obtain the points of intersection of the three following lines:the tangent to the PV curve at the point of a maximum slope, the horizontal line of the initial PV value and the horizontal line of the final value of PV.

- Assign the Deadtime L to the time value from when the step is applied until the first and second lines are cut.

- Assign the time constant $\mathrm{T}$ to the time value from the previous cut-off point to the cut-off point of the first and third lines.

- Assign the process gain $\mathrm{K}$ which is the quotient between the increment of PV and the step width applied to CV.

- $\quad$ Adjust the PID [13] constants according to Table 7.

Table 7: Open-loop setting table of the parameters of a PID controller proposed by Ziegle-Nichols

\begin{tabular}{|c|c|c|c|}
\hline & $\mathbf{K p}$ & $\mathbf{T i}$ & $\mathbf{T d}$ \\
\hline $\mathbf{P}$ & $\frac{T}{L}$ & $\infty$ & 0 \\
\hline $\mathbf{P I}$ & $0,9 \frac{T}{L}$ & $\frac{L}{0,3}$ & 0 \\
\hline PID & $1,2 \frac{T}{L}$ & $2 L$ & $0,5 L$ \\
\hline
\end{tabular}




\subsection{Ziegler-Nichols Rapid Controller Empirical Adjustment Method}

This method is applied when the response is very fast from the induction of an oscillating output. First $\mathrm{Ti}=\infty$ and $\mathrm{Td}=0$ are set. Using only the proportional control action, $\mathrm{Kp}$ is increased from 0 to a critical value Kcr where the output has sustained oscillations [14]-[16]. The values are found in Table 8.

Table 8: Open-loop adjustment of PID parameters proposed by Ziegle-Nichols based on critical gain

\begin{tabular}{|c|c|l|l|}
\hline $\mathbf{K}$ & \multicolumn{1}{|c|}{$\mathbf{T i}$} & \multicolumn{1}{|c|}{ Td } \\
\hline $\mathbf{P}$ & $0.5 \mathrm{~K} c r$ & $\infty$ & 0 \\
\hline $\mathbf{P I}$ & $0.45 \mathrm{Kcr}$ & $\frac{1}{1,2} \mathrm{Pcr}$ & 0 \\
\hline PID & $0.6 \mathrm{Kcr}$ & $0.5 P c r$ & $0.125 \mathrm{Pcr}$ \\
\hline
\end{tabular}

\subsection{Results for each of the stages}

\subsubsection{Filter station}

For this station, the variable to control is the pressure. The method presented in 3.2 proposed by Ziegler-Nichols was used since the response obtained through the Easy-Port and fluid lab is very fast. The characterization of the system is in Figure 7.

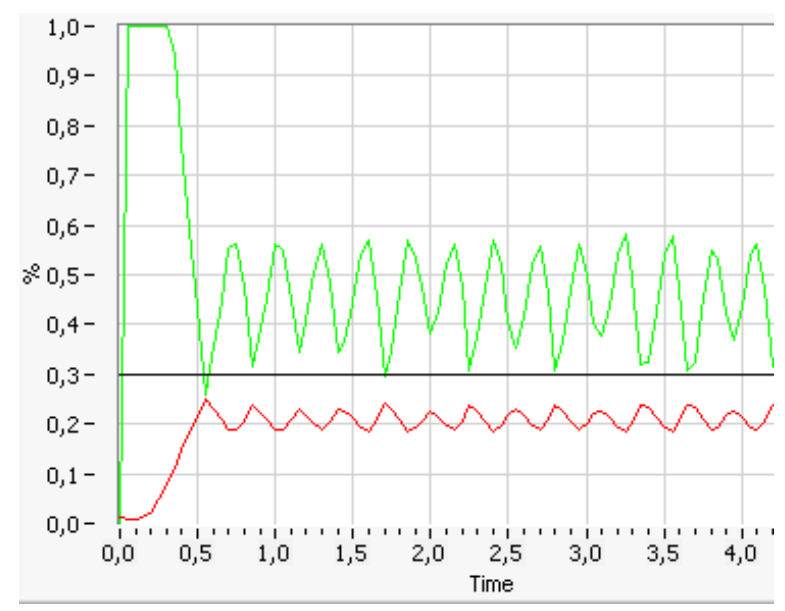

Figure 7: Filter station response using the second Ziegler-Nichols method

The oscillating response of the filtering station was obtained for a critical $\mathrm{K}$ of 5 and by disabling the integral and derivative parameters. To obtain the parameters for PI control, for $\mathrm{Kp}=5$, a critical period of Pcr=0.25 is obtained. From the previous tables, it is mathematically deduced that $\mathrm{Kp}=2.25$ and $\mathrm{Ti}=0.208$. Applying these parameters to the controller the following response was obtained which is shown as a red line in Figure 8. 


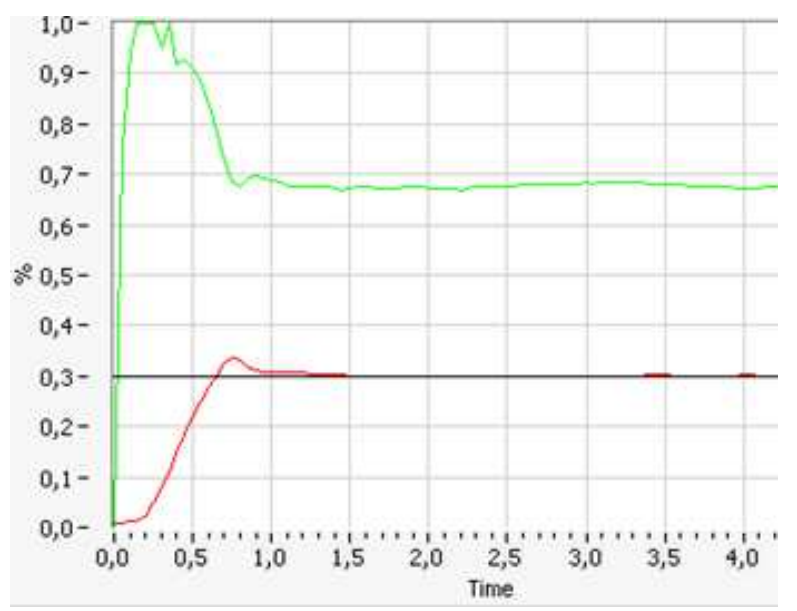

Figure 8: Result of the filtering station with the new tuning parameters

The green line is the voltage applied by the controller.

\subsubsection{Mixing station}

At this station, the response is a little slower than at the filtering station (Figure 9), but not slow enough for its response to having a timeout that can be observed, which is why the second Ziegler-Nichols method is used again. This type of response was obtained for a $\mathrm{Kcr}=10$, which is why a value of $\mathrm{Kp}=5$ and a $\mathrm{Ti}=0.83$ is obtained for a PI type control.

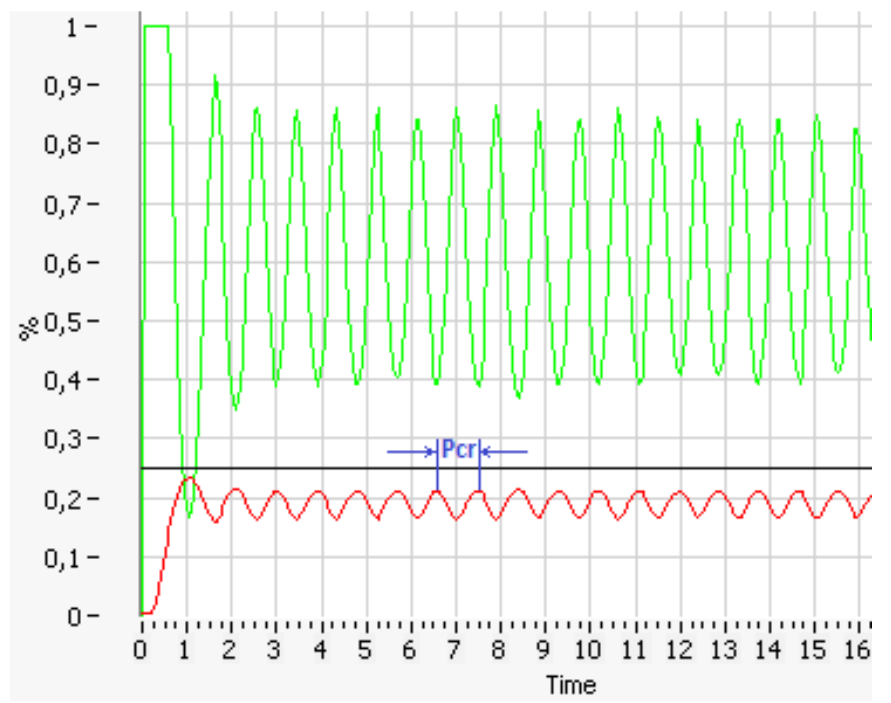

Figure 9: Result at the mixing station using the second Ziegler-Nichols method

For a PID type control we obtain $\mathrm{Kp}=4.5, \mathrm{Ti}=0.5$ and $\mathrm{Td}=0.125$. Conditioning the controller to the new values the response is as shown in Figure 10. 


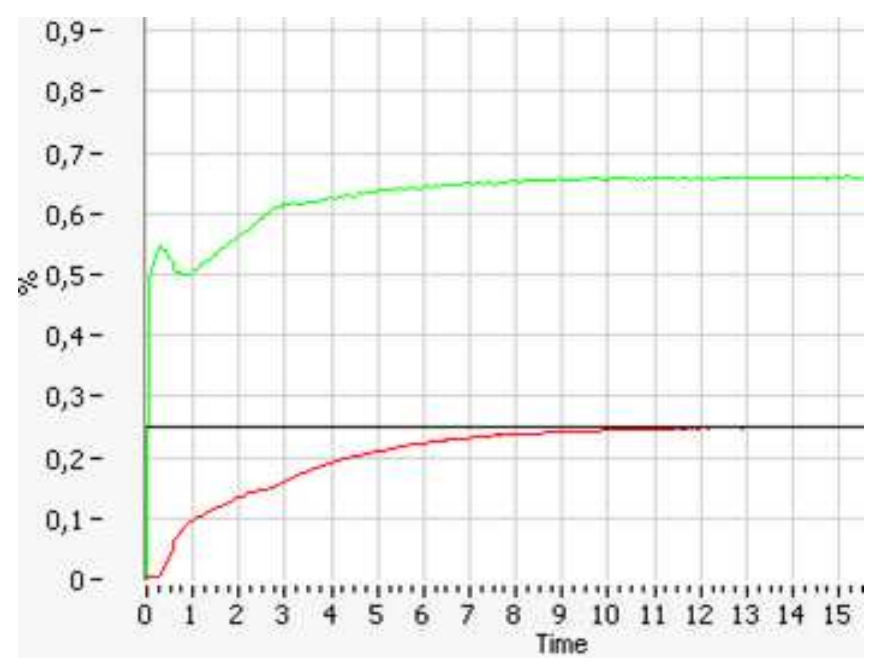

Figure 10: Results at the mixing station with the new tuning parameters

\subsubsection{Mixing station}

For the reactor station, the response is very slow since the variable is the temperature (Figure 11), so there is a dead time and in this way, the necessary conditions are obtained to use the first Ziegler-Nichols method.

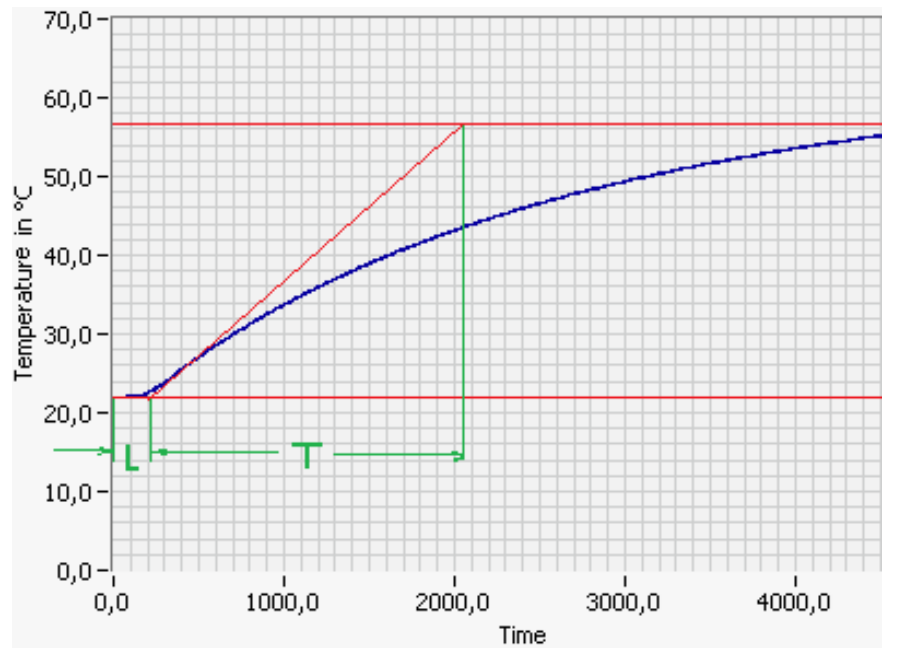

Figure 11: Reactor station response using the first Ziegler-Nichols method

Given the values shown in the Figure 11 , we obtain that the value of $\mathrm{Kp}=12, \mathrm{Ti}=400$ and $\mathrm{Td}=10$. The response after adjusting the parameters of the controller can be seen in Figure 12. 


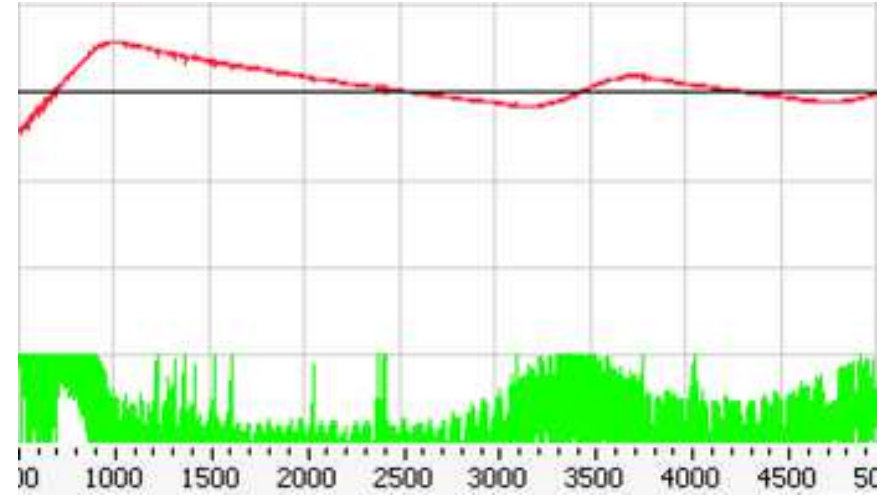

Figure 12: Response of the reactor station applying the new parameters

\subsubsection{Bottlingstation}

For the bottling station, the response is slightly slow since the variable is level and the drainage valve is not completely open, so the filling time is relatively short compared to the reactor station, which is why the first Ziegler-Nichols method is applied, obtaining in the characterization stage the Figure 13.

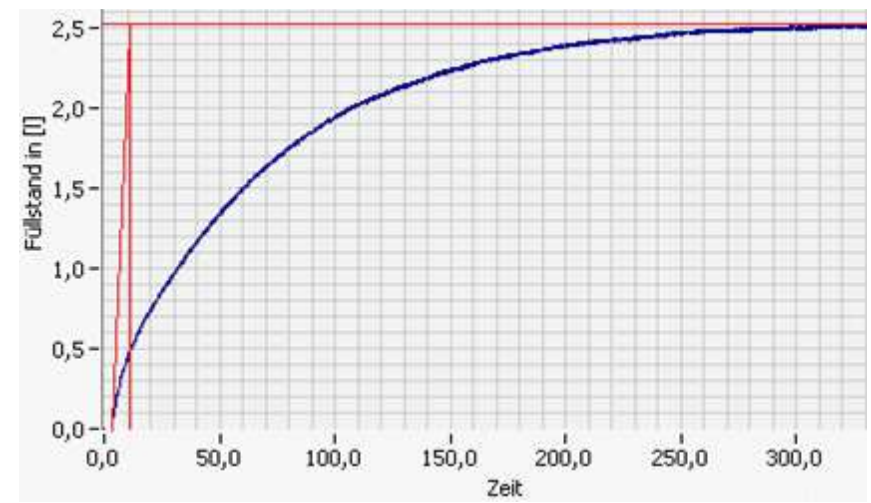

Figure 13: Response of the filling or bottling station by applying the first Ziegler-Nichols method

As you can see in Figure 13 the dead time is very short and the tangent is very pronounced thanks to the fast filling of the tank, which is why the $\mathrm{T}$ and $\mathrm{L}$ times are very small. With $\mathrm{L}=2$ and $\mathrm{T}=5$ we have then that $\mathrm{K}=3, \mathrm{t}=4$ and $\mathrm{td}=1$. With the previous parameters, we obtain the answer shown in the Figure 14.

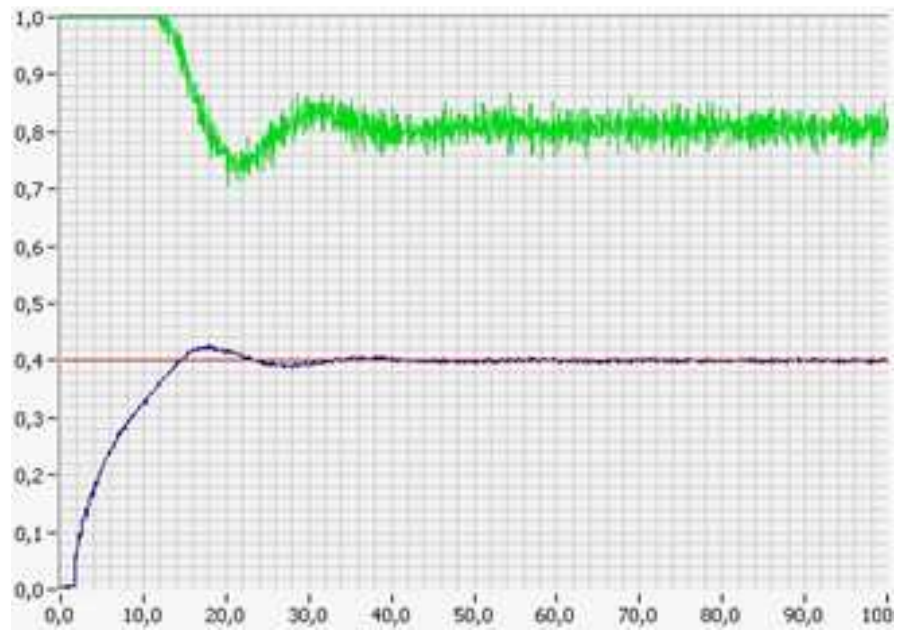

Figure 14: Response of the filling or bottling station by applying the new parameters 


\section{SCADA SYSTEM}

To make the SCADA [17] from Codesys simply press the visualization option where you can make some drawings in a very detailed way being able to determine movement in the objects that you want assigning counters or variables that were or will be created for that purpose.

Having made the program in Codesys some visualization functions can be made pressing the visualization tab that is in the left inferior part. When doing this you will be able to draw each one of the elements that you want and these can act according to the variables that are assigned to them even with movement.With this tool it is possible to create a very complete graphical environment resulting in the appearance for the studied problem shown in Figure 15.

\section{MPS-PA FESTO}

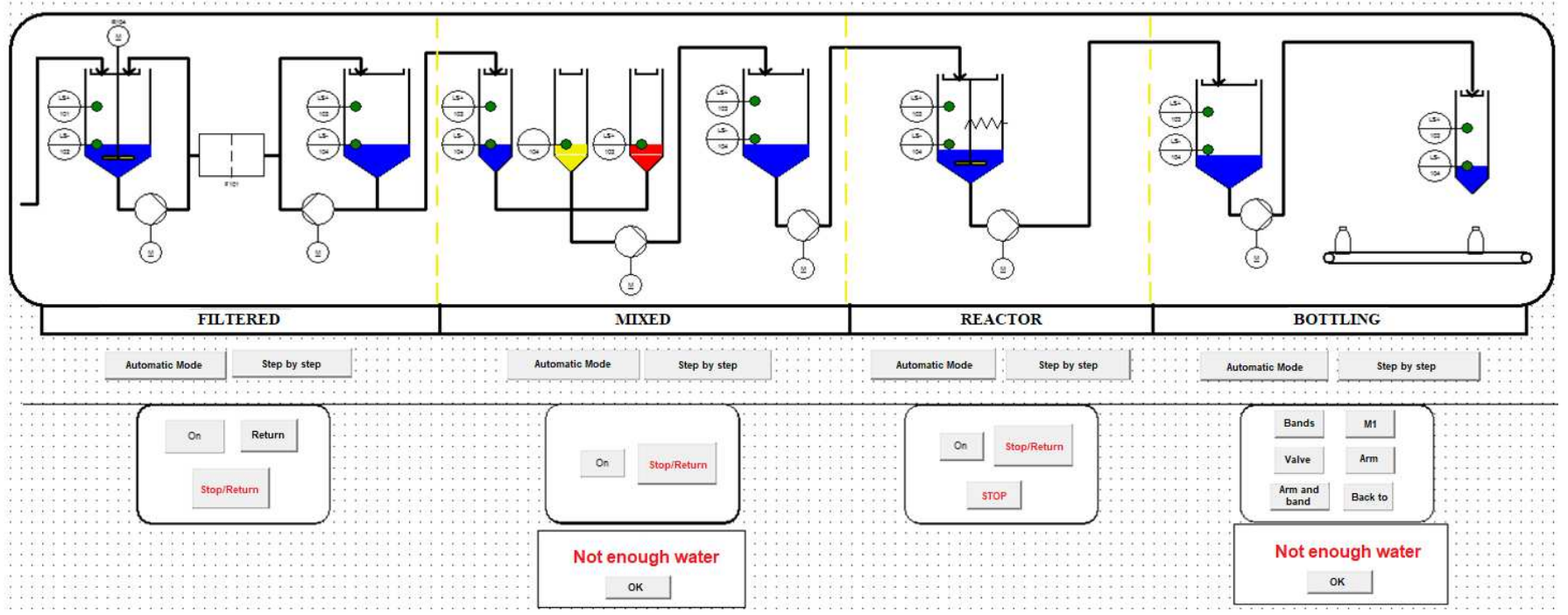

Figure 15: SCADA System

As can be seen in Figure 15, the level of each of the tanks is shown, which will have movement depending on the conditions that were established in the programming of the variables. Also, the sensors will change color along with the elements that correspond to the actuators such as the motors. You can also see some safety conditions that indicate that the tanks are free of water. This message is programmed because pumps can be damaged by vacuum operation.

\section{CONCLUSIONS}

In the programming part of the PLCs, a sequence is made according to the water recycling process using the Grafcet graphic programming language, which allows the process to be analyzed in a simpler way and in this way errors that may occur can be corrected in time. It also complements very well with the structured language which allowed to adjust the necessary variables for the operation of the process.

On the other hand, the Human Machine Interface could be successfully related to the program and control the whole process in a simple way, complying with deactivations of actuators in case of emergency, as well as safety messages on the touch screen that warn the machine operators about the errors that can occur such as the operation of vacuum pumps or opening the filling valve without having a bottle to fill. 
The control that is exercised over the analog actuators of each of the modules using the empirical Ziegler-Nichols method, responds well by saying that the point is always reached within acceptable times. Although some stations respond too quickly due to their nature, it was possible to find the parameters that give excellent control over the variables.

Finally, it was possible to establish a graphic interface that allows the entire process to be controlled remotely, with the safety conditions it requires, observing through moving graphics the amount of water each tank contains, as well as displaying safety messages when the tanks are out of water. Options are also displayed, according to the type of process and those that cannot be used are disabled.

\section{ACKNOWLEDGMENTS}

The authors would like to thank the Universidad Distrital Francisco José de Caldas and the LASER research group that supported the development and testing of the project.

\section{REFERENCES}

1. Rivera, T. (2019). Effects of automation on employment in Chile. Revista de Análisis Económico. 34(1):3-49.

2. Martínez, J. (2017). Vanguardia - Automatización: una necesidad para Colombia. Retrieved from: https://www.vanguardia.com/tecnologia/automatizacion-una-necesidad-para-colombia-OFVL400493

3. Patiño, L. (2018). El Tiempo - Automatización, una oportunidad para hacer negocios sostenibles. Retrieved from: https://www.eltiempo.com/tecnosfera/novedades-tecnologia/se-impulsa-la-nueva-economia-digital-en-colombia-duranteinnovation-day-230570

4. Ogata, K. (2010). Ingeniería de control moderna. 5th ed., Madrid, España: Pearson Educación S.A.

5. Kuo, B. (2004). Sistemas de Control Automático.10th ed., México: Prentice Hall.

6. Dorf, R. \& Bishop, R. H.(2005).Sistemas de Control Moderno. 10th ed., Madrid, España: Pearson Educación S.A.

7. FESTO. (2015). Filtrado, mezclado, templado y llenado como en la industria. Retrieved from: https://www.festodidactic.com/es-es/noticias/2722.htm?fbid=ZXMuZXMuNTQ3LjEOLjE2LjI3MjI

8. FESTO. (2015). MPS® PA - Aplicaciones en la automatización de procesos. Retrieved from: https://www.festodidactic.com/es-es/productos/automatizacion-de-procesos/estaciones/mps-pa-aplicaciones-en-la-automatizacion-deprocesos.htm?fbid=ZXMuZXMuNTQ3LjEOLjE4LjEwODIuNzYOOA

9. Warsaw University of Technology - Faculty of Electrical Engineering.(2003). User manual for PLC programming with CodDeSys 2.3. Retrieved from: https://www.ee.pw.edu.pl/ purap/PLC/manuals/m07590333_00000000_1en.pdf

10. Pillai, B.,Trivedi, D.,Mehta, V. \&Patel, N. (2013). Automation and Virtual Simulation of Laboratory Based Mini Thermal Power Plant. International Journal ofMechanical and Production Engineering Research and Development (IJMPERD).3(4):69-76.

11. Mandado,E., Marcos J., Fernández, C. and Armesto, I. (2009). Autómatas programables y sistemas de automatización. México: Marcombo.

12. Gutiérrez, H. (2012). Automatización Industrial: Teoría y Laboratorio. 3rd ed., Bogotá, Colombia: Universidad Distrital Francisco José de Caldas.

13. Pravallika, K.\&Krishna, G. V. (2020). Fuzzy-PID Controller for Coupled Two Tank Interacting System. International Journal of Mechanical and Production Engineering Research and Development (IJMPERD). 10(3):8817-8830. 
14. Mulik, S. S., Deshmukh, S. P., Shewale, M. S. \&Zambare, H. (2016). Design, Development and Precision Scanning of Single DOF Flexural Mechanism Using Double Flexural Manipulator. ARPN Journal of Engineering and Applied Sciences. 11(13):8342-8348.

15. Creus A. (2011). Instrumentación industrial. 8th ed., México: Alfaomega Grupo Editor.

16. Mazlan, N. N. B. M.,Thamrin, N. M. \&Razak, N. A. (2020). Comparison Between Ziegler-Nichols and AMIGO Tuning Techniques in Automated Steering Control System for Autonomous Vehicle. 2020 IEEE International Conference on Automatic Control and Intelligent Systems (I2CACIS), Shah Alam, Selangor, Malaysia, 2020, pp. 7-12.

17. Sivaranjani, T., Indirapriyadharshini, J., Amarendra, K., Deepak, V., Murugan, G. \&Theerthana, T. (2020). Computerized Control of Cement Roof Manufacturing Process Using PLC and SCADA. International Journal of Advanced Science and Technology. 29(03):9107-9117. 